University of Nebraska - Lincoln

DigitalCommons@University of Nebraska - Lincoln

October 1994

\title{
Ten Generations of Selection for Predicted Weight of Testes in Swine: Direct Response and Correlated Response in Body Weight, Backfat, Age at Puberty, and Ovulation Rate
}

\author{
Rodger K. Johnson \\ University of Nebraska-Lincoln, rjohnson5@unl.edu \\ Gregg R. Eckardt \\ University of Nebraska-Lincoln \\ Thomas A. Rathje \\ University of Nebraska-Lincoln \\ Denise K. Drudik \\ University of Nebraska-Lincoln
}

Follow this and additional works at: https://digitalcommons.unl.edu/animalscifacpub

Part of the Animal Sciences Commons

Johnson, Rodger K.; Eckardt, Gregg R.; Rathje, Thomas A.; and Drudik, Denise K., "Ten Generations of Selection for Predicted Weight of Testes in Swine: Direct Response and Correlated Response in Body Weight, Backfat, Age at Puberty, and Ovulation Rate" (1994). Faculty Papers and Publications in Animal Science. 52.

https://digitalcommons.unl.edu/animalscifacpub/52

This Article is brought to you for free and open access by the Animal Science Department at DigitalCommons@University of Nebraska - Lincoln. It has been accepted for inclusion in Faculty Papers and Publications in Animal Science by an authorized administrator of DigitalCommons@University of Nebraska - Lincoln. 


\title{
Ten Generations of Selection for Predicted Weight of Testes in Swine: Direct Response and Correlated Response in Body Weight, Backfat, Age at Puberty, and Ovulation Rate ${ }^{1,2}$
}

\author{
Rodger K. Johnson, Gregg R. Eckardt ${ }^{3}$, Thomas A. Rathje, and Denise K. Drudik \\ Department of Animal Science, University of Nebraska, Lincoln 68583-0908
}

\begin{abstract}
Selection for predicted weight of testes at $150 \mathrm{~d}$ of age (PWT) was practiced for 10 generations to determine the effect on reproductive and growth traits in swine. Mass selection among boars (line TS) or random selection (line $\mathrm{C}$ ) was practiced beginning with the $F_{3}$ generation of a Large White $\times$ Landrace composite population. Population size in each line was 40 to 45 litters by 15 sires per generation. Responses were estimated by regressions on cumulative selection differentials for PWT and on generation number and by mixed-model derivativefree REML procedures. The realized heritability of PWT was $.35 \pm .02$ and the response per generation was $19 \mathrm{~g}(P<.01)$. Correlated responses in body weight were $.95 \pm .37(140 \mathrm{~d})$ and $1.13 \pm .42 \mathrm{~kg}(160$
\end{abstract}

d) per generation for boars and $.70 \pm .32(130 \mathrm{~d})$ and $.64 \pm .46 \mathrm{~kg}(180 \mathrm{~d})$ per generation for gilts. Response in backfat was $.08 \pm .14 \mathrm{~mm}$ per generation in boars and $.16 \pm .14 \mathrm{~mm}$ in gilts. Negative genetic trends occurred in age at puberty in both lines, but the difference between lines was not significant. At Generation 10, ovulation rate was $.76 \pm .43$ eggs more for gilts of the TS line than for $\mathrm{C}$ gilts. Genetic correlations of PWT with other traits are presented. Heritability of PWT was moderately high and its phenotypic variance was large; therefore, a high rate of response of $5.5 \%$ per generation occurred. Selection for PWT was not effective in decreasing age at puberty or increasing ovulation rate of daughters.

Key Words: Pigs, Testes, Selection, Genetic Correlation, Reproduction, Growth

\section{Introduction}

Land (1973) found differences in ovulation rate of breeds of sheep associated with differences in testis size of rams. He also reported a genetic correlation of .82 between mean ovulation rate and mean testis weight of five mouse lines after 12 generations of selection for ovulation rate. He suggested it might be possible to base selection for fertility in females on reproductive characteristics of males.

Following Land's paper, several researchers found that differences among lines or breeds for ovulation rate, litter size, or age at puberty were correlated with differences in size of testes (swine: Proud et al., 1976;

\footnotetext{
${ }^{1}$ Published as paper no. 10451, Journal Ser., Nebraska Agric. Res. Div., Univ. of Nebraska, Lincoln 68583-0908.

${ }^{2}$ Acknowledgments to K. Meyer, K. G. Boldman, and L. D. Van Vleck for the mixed-model program and to L. D. Young for reviewing the manuscript and providing useful suggestions on interpretation of the data.

${ }^{3}$ Current address: Pig Improvement Co., P.O. Box 348, Franklin, KY 42134.

Received August 11, 1993.

Accepted March 15, 1994.
}

Schinckel et al., 1983; sheep: Land and Carr, 1975; Hanrahan and Quirke, 1977). A significant positive response occurred in ovulation rate from selection for weight of testes in mice (Islam et al., 1976).

Because larger selection differentials are possible in males, selection response could be enhanced by including a male indicator trait along with direct measures of fertility in females. The emphasis to give the trait depends on its heritability and its genetic correlation with other economic traits.

Selection for predicted weight of testes was initiated in 1981 to determine the effects on reproductive and growth traits in swine. This paper reports genetic analyses of direct response and correlated responses in body weight, backfat thickness, ovulation rate, and age at puberty after 10 generations of selection.

\section{Materials and Methods}

Population. In 1979, 12 Landrace boars were mated to 39 Large White females and 13 Large White boars were mated to 20 Landrace females to develop a composite population. One boar from each half-sib family and one gilt from each litter were randomly 
selected from the $F_{1}$ litters. These boars and gilts were mated randomly and produced $46 \mathrm{~F}_{2}$ litters by 19 sires.

Boars and gilts of the $\mathrm{F}_{2}$ generation were selected randomly and assigned to three lines. Forty-five boars, three from each of 15 paternal half-sib families, were assigned to lines so that each half-sib family was represented in each line and all boars in each line were from different litters. Gilts were assigned randomly within litter to lines with as many litters as possible represented in each line.

The lines were $\mathbf{C}$, a randomly selected control; TS, a line selected for increased predicted weight of testes (PWT); and a third line selected for an objective not pertinent to this paper. Matings were random in each line and 41 litters were born in 1981 in both lines C and TS. Parents of these litters were from a total of 43 $\mathrm{F}_{2}$ litters; however, only 28 of these litters were represented by parents in both lines $\mathrm{C}$ and TS, whereas eight were represented only in line $\mathrm{C}$ and seven only in line TS.

Hereafter, the $F_{3}$ generation is denoted as Generation 0 of the experiment. Selection was practiced for 10 generations. Population size was 40 to 45 litters by 15 sires each generation for each line.

Selection Criteria. Width and length of paired testes were measured with calipers at approximately 140 and $160 \mathrm{~d}$ of age. Measurements were made weekly so all boars were measured within $4 \mathrm{~d}$ of these ages. Regression coefficients calculated from data on boars of the $F_{1}$ and $F_{2}$ generations (Schinckel et al., 1983) were used to adjust the measurements to width and length at 140 and $160 \mathrm{~d}$ of age.

During the period when the experiment was designed, R. B. Land (personal communication) advised that selection for size of testes at a constant age unadjusted for body weight be practiced. He and coworkers were practicing divergent selection for diameter of testes in rams measured at 6,10 , and 14 wk of age adjusted for body weight. After $6 \mathrm{yr}$, rams of the low line were heavier than rams of the high line and weights of ewes at 1.5 and $2.5 \mathrm{yr}$ of age were higher for the low line. Because of the adjustment, responses in body weight were difficult to interpret (Land et al., 1980).

Schinckel et al. (1983) found that there was a rapid growth of testes from 80 to $140 \mathrm{~d}$ of age and maximum differences between lines existed at ages of 140 and $160 \mathrm{~d}$. Correlations of width and length of testes with weight of testes were similar at ages from 120 to $180 \mathrm{~d}$. Therefore, we chose to take measurements at both 140 and $160 \mathrm{~d}$ to increase the accuracy of predicting weight of testes.

The equation used to predict weight (grams) of paired testes at $150 \mathrm{~d}$ of age was PWT $=12.5 \times \mathrm{W} 140+$ $20 \times \mathrm{L} 140+16 \times \mathrm{W} 160+32 \times \mathrm{L} 160-508.3$, where $\mathrm{W}$ and $\mathrm{L}$ are width and length of paired testes (centimeters), respectively, adjusted to 140 and $160 \mathrm{~d}$ of age. The equation was derived from variances and covariances among these measurements and of these measurements with weights of excised testes that were reported by Schinckel et al. (1983). The correlation between PWT and weight of testes was calculated to be .92 .

Mass selection was practiced in the TS line. In each generation, width and length of testes were measured on all boars and the 30 boars with the largest PWT were retained. The 15 highest ranking boars were used as breeders. The other 15 boars were retained and used as breeders in the order of their rank for PWT only if a primary boar failed to mate. Gilts were selected randomly with the restriction that at least one gilt was selected from each litter.

Random within-family selection was practiced in line $\mathrm{C}$. One boar to be used as a breeder and one alternate for this boar were selected from each of the 15 half-sib families each generation. At least one gilt from each full-sib family was selected.

Management and Traits Measured. Diets and the feeding regimen used during each phase of the production cycle are described in Table 1 . Throughout their lives, pigs were in buildings in which the environment was regulated.

During the breeding period, gilts were in a confinement barn with 10 gilts per pen and they were checked daily for signs of estrus. Gilts were randomly assigned to boars, except full- and half-sib matings were avoided. Gilts were hand-mated to boars each day they would mate.

Gilts were in individual stalls during the gestation period. Farrowing occurred in environmentally controlled rooms with 12 crates per room. All pigs were weighed within $24 \mathrm{~h}$ of birth. To the extent possible,

Table 1. Formulated values (as-fed basis) of crude protein (CP), lysine, and metabolizable energy (ME) of diets ${ }^{a}$ fed during each phase ${ }^{b}$ of production

\begin{tabular}{|c|c|c|c|}
\hline Phase & $\mathrm{CP}, \%$ & Lysine, \% & $\begin{array}{c}\mathrm{ME}, \\
\mathrm{kcal} / \mathrm{kg}\end{array}$ \\
\hline \multicolumn{4}{|l|}{ Nursery } \\
\hline Day 1 to 7 & 21.0 & 1.40 & 3,475 \\
\hline \multicolumn{4}{|l|}{ Day 7 to avg wt per } \\
\hline $12 \mathrm{~kg}$ to $56 \mathrm{~d}$ of age & 18.2 & 1.00 & 3,396 \\
\hline \multicolumn{4}{|l|}{$56 \mathrm{~d}$ of age to avg pen } \\
\hline $\mathrm{wt}=55 \mathrm{~kg}$ & 16.0 & .80 & 3,288 \\
\hline $55 \mathrm{~kg}$ to mating & 14.0 & .67 & 3,305 \\
\hline Gestation & 11.5 & .52 & 3,180 \\
\hline Lactation & 13.2 & .67 & 3,350 \\
\hline \multicolumn{4}{|c|}{ 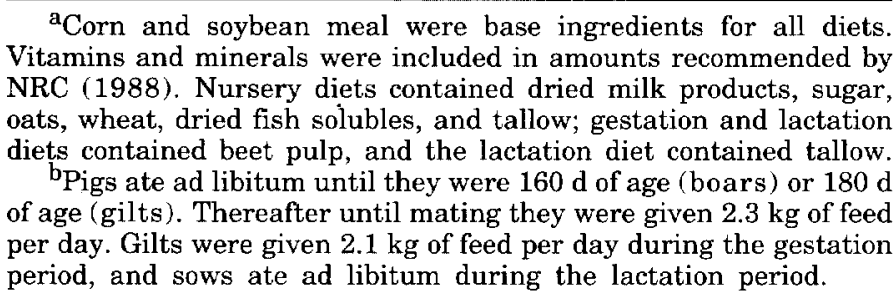 } \\
\hline
\end{tabular}


some randomly selected pigs from large litters were moved to smaller litters, both within and across lines, to reduce variation in the number of pigs nursed by sows. Sows generally nursed 10 pigs or fewer. Transferred pigs were eligible for selection.

Litters were weaned at $28 \mathrm{~d}$ of age and placed in environmentally controlled nursery rooms with 10 pens per room. Approximately 25 pigs of one sex were in each pen. At approximately $56 \mathrm{~d}$ of age, all boars from the TS line, 30 boars from the $\mathrm{C}$ line, and 50 to 55 gilts per line were moved to buildings in which temperature and ventilation were regulated with adjustable doors over openings on each side. Each building contained pigs of one sex. Each pen contained 10 pigs of similar age from both lines.

Boars were weighed when testes were measured and their backfat was measured with a sonoray instrument (Renco Lean-Meter, Type LM-7, Minneapolis, MN) when 160-d measurements were made. Backfat was measured 4 to $5 \mathrm{~cm}$ off the midline at approximately the locations of the fourth rib, last rib, and last lumbar vertebra. These three measurements were averaged.

All gilts in each pen were weighed when the oldest pig in the pen was $135 \mathrm{~d}$ of age during Generations 0 to 4 , and $130 \mathrm{~d}$ of age thereafter. Beginning at these ages, gilts were taken daily to an adjacent building where they were allowed to interact with a boar for 15 to $20 \mathrm{~min}$ and observed for signs of estrus. Age when a gilt first stood immobile for the boar and exhibited the typical symptoms of estrus was recorded as age at puberty. Gilts were weighed and their backfat was measured at approximately $180 \mathrm{~d}$ of age.

Each year gilts were observed daily for signs of estrus until they were observed in estrus or until the end of the breeding period when the youngest gilt was approximately $250 \mathrm{~d}$ of age. During the experiment, estrus was not observed for eight C-line and six TSline gilts. Records for these gilts were not used in analyses of age at puberty.

During Generations 5 and 10 , a larger sample of gilts was retained so ovulation rate could be determined. An additional 32 gilts per line were randomly chosen in Generation 5. They were slaughtered 10 to $15 \mathrm{~d}$ after their second estrous period and their reproductive tracts were collected. Ovulation rate was measured by dissecting the ovaries and counting the corpora lutea. In Generation 10, laparotomy was done 10 to $15 \mathrm{~d}$ after the second estrous period on 42 gilts from the TS line and 40 from the $\mathrm{C}$ line and corpora lutea on the ovaries were counted.

The number of animals measured for each trait is given in Table 2. During the eighth and ninth generations, a random sample of 75 boars of each line was selected at weaning for another experiment. Thus, sample size and selection intensity were lower in these generations. Only a sample of gilts was observed for their pubertal estrus in Generation 0 .

\section{Data Analyses}

Responses to selection were estimated in two ways. The first method, regression analysis, used regressions of traits on generation number and on cumulative selection differential for PWT. The second method, mixed-model analysis, used an animal model and REML procedures to estimate variance components. Average breeding values were calculated for each line to estimate genetic trends. First, however, analyses were done to test heterogeneity of variances of PWT across lines and generations.

Test for Heterogeneous Variance. Line-generation means and standard deviations for PWT are given in

Table 2. Numbers of observations for traits measured on boars and gilts by line a and generation

\begin{tabular}{|c|c|c|c|c|c|c|c|c|c|c|}
\hline \multirow[b]{3}{*}{ Generation } & \multirow{2}{*}{\multicolumn{2}{|c|}{ Boars $^{b}$}} & \multicolumn{8}{|c|}{ Gilts $^{c}$} \\
\hline & & & \multicolumn{2}{|c|}{ BW130 } & \multicolumn{2}{|c|}{ BW180 \& BF } & \multicolumn{2}{|c|}{$\mathrm{AP}$} & \multicolumn{2}{|c|}{ OR } \\
\hline & $\mathrm{C}$ & TS & $\mathrm{C}$ & TS & $\mathrm{C}$ & TS & $\mathrm{C}$ & $\mathrm{TS}$ & $\mathrm{C}$ & $\mathrm{TS}$ \\
\hline 0 & 31 & $138^{\mathrm{d}}$ & 52 & 52 & 48 & 51 & 31 & 34 & - & - \\
\hline 1 & 29 & 187 & 54 & 53 & 54 & 52 & 54 & 52 & - & - \\
\hline 2 & 33 & 158 & 53 & 55 & 53 & 55 & 53 & 55 & - & - \\
\hline 3 & 30 & 166 & 56 & 56 & 56 & 55 & 55 & 55 & - & 一 \\
\hline 4 & 30 & 156 & 55 & 56 & 55 & 56 & 55 & 56 & - & - \\
\hline 5 & 30 & 140 & 91 & 90 & 52 & 54 & 87 & 87 & 31 & 32 \\
\hline 6 & 34 & 147 & 56 & 56 & 56 & 55 & 54 & 55 & 一 & - \\
\hline 7 & 31 & 145 & 56 & 54 & 56 & 54 & 55 & 52 & - & - \\
\hline 8 & 31 & 78 & 54 & 51 & 54 & 51 & 54 & 51 & - & - \\
\hline 9 & 32 & 84 & 49 & 49 & 49 & 49 & 49 & 49 & - & - \\
\hline 10 & 31 & 136 & 104 & 103 & 100 & 101 & 103 & 98 & 40 & 42 \\
\hline
\end{tabular}

a TS = line selected for increased size of testes, $\mathrm{C}=$ control line.

b Traits of boars are predicted weight of testes, body weight at 140 and $160 \mathrm{~d}$ of age, and backfat thickness at $90 \mathrm{~kg}$.

cTraits of gilts are body weight at $130 \mathrm{~d}$ of age (BW130) and at $180 \mathrm{~d}$ of age (BW 180), backfat thickness at $90 \mathrm{~kg}$ (BF), age at puberty

(AP) and ovulation rate at the second estrus cycle (OR).

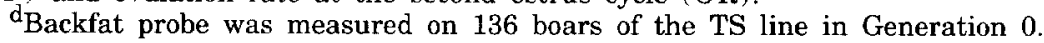


Table 3. Means, standard deviations, and realized cumulative selection differentials ${ }^{a}$ for predicted weight of testes at 150 days of age $(\mathrm{g})$ by $\operatorname{line}^{\mathrm{b}}$ and generation

\begin{tabular}{|c|c|c|c|c|c|c|c|c|c|c|}
\hline \multirow[b]{2}{*}{ Generation } & \multicolumn{5}{|c|}{ C line } & \multicolumn{5}{|c|}{ TS line } \\
\hline & $\overline{\mathbf{x}}$ & $\mathrm{SD}$ & $\mathrm{S}$ & $\mathbf{S}^{\prime}$ & $\mathrm{F}, \% \mathrm{c}$ & $\overline{\mathrm{x}}$ & $\mathrm{SD}$ & $\mathrm{S}$ & $\mathrm{S}^{\prime}$ & $\mathrm{F}, \% \mathrm{c}$ \\
\hline 0 & 410.5 & 66.1 & - & - & 0 & 413.6 & 72.9 & - & - & 0 \\
\hline 1 & 365.2 & 84.3 & -4.0 & - & 0 & 414.8 & 83.8 & 126.1 & - & .15 \\
\hline 2 & 400.0 & 59.2 & 39.2 & -.8 & .96 & 481.4 & 66.5 & 190.4 & 60.6 & 1.42 \\
\hline 3 & 349.3 & 56.6 & 23.5 & 12.6 & 1.50 & 447.1 & 69.8 & 252.0 & 124.9 & 2.12 \\
\hline 4 & 371.3 & 65.4 & -6.4 & 36.5 & 1.81 & 472.2 & 81.5 & 342.1 & 194.9 & 3.76 \\
\hline 5 & 330.3 & 73.5 & -12.9 & 19.3 & 3.35 & 446.7 & 68.2 & 429.9 & 272.0 & 5.83 \\
\hline 6 & 316.4 & 69.7 & 28.2 & -6.7 & 3.94 & 456.0 & 87.6 & 444.6 & 350.5 & 6.68 \\
\hline 7 & 411.6 & 66.9 & 16.6 & .6 & 4.50 & 553.6 & 67.8 & 518.8 & 396.0 & 7.98 \\
\hline 8 & 311.5 & 68.0 & 18.9 & -1.4 & 6.09 & 517.0 & 81.1 & 576.8 & 466.8 & 8.97 \\
\hline 9 & 300.7 & 64.8 & 1.0 & 8.5 & 6.04 & 469.5 & 82.1 & 632.2 & 518.8 & 10.51 \\
\hline 10 & 337.4 & 95.9 & 19.4 & 2.1 & 7.30 & 555.7 & 79.7 & 670.2 & 585.5 & 11.49 \\
\hline
\end{tabular}

${ }^{a} \mathrm{~S}$ and $\mathrm{S}^{\prime}$ are cumulative selection differentials of sires and dams, respectively.

${ }^{b} \mathrm{C}=$ control line, $\mathrm{TS}=$ line selected for increased predicted weight of testes.

${ }^{\mathrm{c}} \mathrm{F}=$ mean percentage inbreeding.

Table 3. All measurements of testes within generations were done by one person, but during the experiment four different people made these measurements. Considerable variability in both the mean and standard deviation of PWT existed among generations and lines. Some of the variation among means over generations was most likely due to technicians applying different amounts of pressure with the calipers when measuring testes. Because lines were treated equally within generation, this source of variability is accounted for by the analyses, which are described below, as environmental effects of generations.

An analysis that considered heterogeneous variances would have been appropriate if there was a consistent pattern in variances associated with either lines or generations. Therefore, the chi-square test for homogeneity of variances (Steel and Torrie, 1960) and the method of regressing standard deviations on generation number were used to test whether variability differed between lines and whether variability changed over time because of selection.

Three hypotheses were tested by chi-square. The first tested whether variances within line $\mathrm{C}$ were equal for all generations and the second tested this hypothesis for line TS. The hypothesis was not rejected for the $\mathrm{C}$ line $(P>.10)$, but heterogeneous variances were found for line TS $(P<.01)$. The third hypothesis was that the pooled variances for the lines were equal. Although the pooled variance for line TS $\left(\mathrm{s}^{2}=5849.2, \mathrm{SD}=76.5 \mathrm{~g}\right)$ was $17 \%$ larger than the pooled variance for line $\mathrm{C}\left(\mathrm{s}^{2}=5000.6, \mathrm{SD}=70.7\right)$, the $P$-value for the calculated chi-square for the test of equality of variances was $.1>P>.05$. Therefore, the hypothesis of equality of pooled variances was not rejected.

In the regression analysis, standard deviations were fitted to a model that included line, regression on generation number, and line $\times$ regression interaction. Average standard deviations did not differ between lines ( $P=.14$ ), there was no evidence for a line $\times$ regression interaction $(P>.50)$, and the within-line regressions were not different from zero $(\hat{b}=1.11 \pm$ .91 for line $\mathrm{C}, \hat{\mathrm{b}}=.66 \pm .91$ for line TS).

Based on these results, we concluded that there was no change in variability associated with selection. The pattern of high and low variability across generations seemed to be random. Therefore, heterogeneous variances were not considered in the analyses.

Regression Analyses. Least squares means were obtained by analyzing each trait with a model that included the effects of line, generation, and line $x$ generation interaction. The GLM procedures of SAS (1988) were used. Age was added to this model as a covariate for body weights at the different ages and weight was added as a covariate for backfat thickness. Data for boars and gilts were analyzed separately.

Regression coefficients from these analyses were used to adjust body weights of boars measured at approximately 140 and $160 \mathrm{~d}$ to weight at $140 \mathrm{~d}$ (BW140) and weight at $160 \mathrm{~d}$ (BW160). Weights of gilts at approximately 130 and $180 \mathrm{~d}$ were adjusted to weight at $130 \mathrm{~d}$ (BW130) and weight at $180 \mathrm{~d}$ (BW180). Backfat of boars was adjusted to the mean weight of $85.3 \mathrm{~kg}$ when they were measured (BF) and backfat of gilts was adjusted to the mean weight of $91.7 \mathrm{~kg}$ when they were measured. No covariate was fitted for PWT and age at puberty ( AP). The general form of all adjustments, illustrated for BW140 ( $b=$ regression of weight on age), was as follows: BW140= actual weight + b (140 - actual age).

Actual records for PWT and AP and adjusted records for body weights and backfat for each animal in the TS line were deviated from the corresponding generation mean for the $\mathrm{C}$ line, and these deviations were regressed on generation number to estimate responses per generation.

The procedure described by Richardson et al. (1968) was used to estimate responses per unit of 
selection differential for PWT. Selection differentials were calculated for each selected boar by deviating its PWT from the line-generation mean. Cumulative selection differentials for boars were calculated as the average cumulative selection differential of the boar's parents plus the boar's selection differential. Cumulative selection differentials for gilts were obtained by averaging the cumulative selection differential of the gilt's parents.

Offspring records for each trait were regressed on the mean cumulative selection differential of the parents while simultaneously fitting generation number and the covariate age or weight, if appropriate for the trait. The regression model was as follows:

$$
\begin{aligned}
Y_{i j k}= & A \ldots+G_{i} \ldots+B_{1} X_{i j k} \\
& +B_{2}\left[\frac{1}{2}\left(S_{i j k}+S_{i j k}^{\prime}\right)\right]+E_{i j k},
\end{aligned}
$$

where $\mathrm{Y}_{\mathrm{ijk}}=$ trait measured on the $\mathrm{k}^{\text {th }}$ animal of the $\mathrm{j}^{\text {th }}$ line in Generation i (PWT, BW140, BW160, and BF of boars; BW130, BW180, BF, and AP of gilts); A.. = expected performance in Generation $0 ; \mathrm{G}_{\mathrm{i} . .}=$ environmental effect common to each line in Generation $\mathrm{i} ; \mathrm{B}_{1}=$ linear regression coefficient on trait $\mathrm{X}(\mathrm{X}=$ age for BW140, BW160, BW130, and BW180; $\mathrm{X}=$ weight for $\mathrm{BF}$; no covariate was fitted for PWT or AP); $\mathrm{B}_{2}=$ linear regression coefficient on the mean cumulative selection differential for PWT of sire $\left(S_{i j k}\right)$ and dam $\left(S_{\mathrm{ijk}}^{\prime}\right)$ of the individual; and $E_{\mathrm{ijk}}=$ random error.

The value of $\hat{\mathrm{B}}_{2}$ estimates realized heritability for PWT, and estimates $r_{g} \sigma_{\mathrm{a}_{\mathrm{y}}} \frac{\mathrm{h}_{\mathrm{PWT}}}{\sigma_{\mathrm{P}_{\mathrm{PWT}}}}$ for analysis of correlated trait $\mathrm{Y}$ (Rutledge et al., 1973), where $r_{\mathrm{g}}$ is the genetic correlation of $Y$ with PWT, $\sigma_{a_{y}}$ is the additive genetic standard deviation of $\mathrm{Y}$, hPWT is the square root of heritability of PWT, and $\sigma_{\mathrm{P}_{\mathrm{PWT}}}$ is the phenotypic standard deviation of PWT. The regression coefficients were multiplied by the ratio $\frac{\hat{\sigma}_{\mathrm{P}_{\mathrm{PWT}}}}{\hat{\sigma}_{\mathrm{a}_{\mathrm{y}}} \hat{\mathrm{h}}_{\mathrm{PWT}}}$ to obtain estimates of genetic correlations of traits with PWT. The realized heritability from the regression analysis was used to obtain h. genetic and phenotypic standard deviations were obtained from results of the mixed-model analyses described below.

Inbreeding coefficients were calculated for each line and generation to estimate effective population size. These values were used in procedures described by Hill (1972) and Notter et al. (1976) to adjust standard errors of regressions on generation number and on cumulative selection differential for genetic drift variance.

Mixed-Model Analyses. In this procedure, traits were fitted to an animal model using multiple-trait derivative-free REML (DFREML) methodology (Boldman et al., 1993) based on the program of Karin Meyer (Meyer, 1988) and the DFREML algorithm of Smith and Graser (1986) and Graser et al. (1987). Analyses were accomplished using DFREML adapted to use SPARSPAK (a licensed product from The Computer Science Department, University of Waterloo, ON, Canada; George et al., 1980), as modified by Boldman and Van Vleck (1991) to do multivariate analyses.

First, estimates of parameters were obtained for PWT by analyzing this variable alone because it was the selected trait. Then, each correlated trait was paired with PWT and a bivariate analysis was done. However, in each bivariate analysis, the parameters for PWT were set to those obtained from the univariate analysis and solutions for genetic parameters for the correlated trait and of the genetic correlation of this trait with PWT were obtained. This procedure was recommended by Sorensen and Johansson (1992) because if parameters for PWT were not held constant in the bivariate analyses, different estimates of them would occur each time PWT was paired with another trait.

The mixed model for each analysis included the fixed effects of generations and the covariates as appropriate for each trait as described for the regression analyses, random animal additive genetic effects, random effects of litters excluding additive genetic effects common to littermates, but including nonadditive genetic and environmental effects common to littermates, and the residual, or random environmental, effect. Pedigree information beginning with Generation 0 was used to calculate the inverse of the numerator relationship matrix.

From these analyses, estimates of phenotypic variance, additive genetic variance, litter variance, environmental variance, heritability, and the ratio of litter variance:phenotypic variance were obtained for trait. Estimates of genetic and phenotypic correlations of PWT with other traits were obtained from the bivariate analyses.

Iterations were assumed to have converged when the difference in variances of successive log likelihoods was less than $10^{-9}$. After convergence was obtained, one more run was performed with parameters set at the converged values and breeding values were obtained for each animal. These values were averaged by line and generation and average values were regressed on generation number to obtain estimates of genetic trend.

Ovulation Rate. Because ovulation rate data were collected only in two generations, it was not analyzed with the regression method. Ovulation rate was fitted to a model that included the effects of line, generation, line $\times$ generation, and sire within line of gilt. The GLM procedures of SAS (1988) were used. Litter effects were not included in the model because there 
Table 4. Least squares means $\mathrm{s}^{\mathrm{a}}$ by line $^{\mathrm{b}}$ and generation and pooled within

line-generation standard deviations for secondary $\operatorname{traits}^{\mathrm{C}}$ measured on boars

\begin{tabular}{|c|c|c|c|c|c|c|}
\hline \multirow[b]{2}{*}{ Generation } & \multicolumn{2}{|c|}{ BW140, kg } & \multicolumn{2}{|c|}{ BW160, kg } & \multicolumn{2}{|c|}{$\mathrm{BF}, \mathrm{mm}$} \\
\hline & $\mathrm{C}^{\mathrm{c}}$ & $\mathrm{TS}^{\mathrm{c}}$ & $\mathrm{C}$ & $\mathrm{TS}$ & $\mathrm{C}$ & TS \\
\hline 0 & 76.1 & 75.9 & 87.1 & 86.7 & 17.8 & 18.7 \\
\hline 1 & 62.4 & 60.2 & 78.6 & 75.3 & 21.6 & 21.8 \\
\hline 2 & 70.6 & 71.7 & 87.3 & 88.3 & 17.2 & 18.3 \\
\hline 3 & 66.6 & 70.5 & 79.6 & 83.1 & 17.4 & 19.3 \\
\hline 4 & 64.9 & 68.8 & 79.5 & 83.3 & 21.2 & 22.8 \\
\hline 5 & 66.5 & 71.3 & 81.4 & 87.2 & 18.4 & 19.3 \\
\hline 6 & 70.1 & 74.5 & 85.0 & 90.3 & 20.5 & 19.6 \\
\hline 7 & 67.9 & 71.7 & 83.4 & 87.4 & 18.6 & 20.7 \\
\hline 8 & 68.5 & 80.2 & 83.5 & 95.3 & 18.7 & 20.3 \\
\hline 9 & 67.7 & 75.3 & 80.8 & 89.3 & 21.4 & 23.0 \\
\hline 10 & 64.8 & 71.9 & 79.7 & 88.0 & 18.8 & 20.5 \\
\hline $\mathrm{SD}$ & \multicolumn{2}{|c|}{10.2} & \multicolumn{2}{|c|}{11.2} & \multicolumn{2}{|c|}{3.6} \\
\hline
\end{tabular}

${ }^{a}$ Model included generation, line, generation $\times$ line plus covariate of age for BW140 and BW160 (mean ages were 140 and $160 \mathrm{~d}$ ), or body weight for BF (mean weight was $85.3 \mathrm{~kg}$ ).

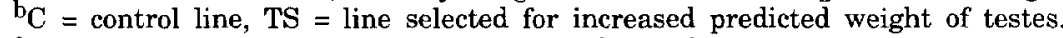

${ }^{\mathrm{C}} \mathrm{BW140}=$ body weight at $140 \mathrm{~d}, \mathrm{BW160}=$ body weight at $160 \mathrm{~d}$, and BF = average backfat thickness at $85.3 \mathrm{~kg}$.

were very few littermates in the sample. Comparisons of the line means were made at each generation.

\section{Results}

The average increase in cumulative selection differential (CSD) of sires and dams was $63 \mathrm{~g}$ per generation and at Generation 10 mean PWT was $218.3 \mathrm{~g}$ more for the TS line than for the C line (Table 3 ). The rate of inbreeding was $.73 \%$ per generation in line $\mathrm{C}$ and $1.15 \%$ in line TS. These values were used in calculations to adjust standard errors of regression coefficients for genetic drift. Least squares means by line and generation for other traits measured on boars are given in Table 4 and means for traits measured on gilts are given in Table 5 .

Average estimated breeding values for each generation are shown in Table 6. There was little genetic change in PWT in line $\mathrm{C}$, but a positive trend occurred for all body weights and a negative trend occurred for AP. In line TS, steady increases in estimated breeding values occurred for PWT, body weights, and BF. Average breeding value for AP decreased sharply in the first two generations and then declined gradually through Generation 8. Thereafter, little change in AP occurred in line TS.

Estimates of responses per unit of CSD by the regression method and per generation by both the regression and the mixed-model methods are given in

Table 5. Least squares means $\mathrm{s}^{\mathrm{a}}$ by $\operatorname{line}^{\mathrm{b}}$ and generation and pooled within line-generation standard deviations for traits ${ }^{\mathrm{C}}$ measured on gilts

\begin{tabular}{|c|c|c|c|c|c|c|c|c|}
\hline \multirow[b]{2}{*}{ Generation } & \multicolumn{2}{|c|}{ BW130, kg } & \multicolumn{2}{|c|}{ BW180, kg } & \multicolumn{2}{|c|}{$\mathrm{BF}, \mathrm{mm}$} & \multicolumn{2}{|c|}{$\mathrm{AP}, \mathrm{d}$} \\
\hline & $\mathrm{C}$ & TS & $\mathrm{C}$ & TS & $\mathrm{C}$ & TS & $\mathrm{C}$ & TS \\
\hline 0 & 63.4 & 63.0 & 90.4 & 91.4 & 19.7 & 20.7 & 182.3 & 176.2 \\
\hline 1 & 50.9 & 53.0 & 84.0 & 87.8 & 22.4 & 23.0 & 193.7 & 180.5 \\
\hline 2 & 65.4 & 63.0 & 94.5 & 93.0 & 18.3 & 19.8 & 185.1 & 171.8 \\
\hline 3 & 57.9 & 60.4 & 89.7 & 95.4 & 18.0 & 20.2 & 191.0 & 175.8 \\
\hline 4 & 57.9 & 60.4 & 89.6 & 93.8 & 21.7 & 23.3 & 185.7 & 169.5 \\
\hline 5 & 58.1 & 61.5 & 89.5 & 95.9 & 19.2 & 20.8 & 181.1 & 179.0 \\
\hline 6 & 58.8 & 65.7 & 92.4 & 102.8 & 19.0 & 22.1 & 176.8 & 173.6 \\
\hline 7 & 55.9 & 63.5 & 89.8 & 96.0 & 18.3 & 20.9 & 171.0 & 169.3 \\
\hline 8 & 57.1 & 62.7 & 94.6 & 100.6 & 20.3 & 22.5 & 176.1 & 169.4 \\
\hline 9 & 58.7 & 64.1 & 92.2 & 97.8 & 20.9 & 23.9 & 180.2 & 174.7 \\
\hline 10 & 57.8 & 63.4 & 91.1 & 98.9 & 19.7 & 21.9 & 181.7 & 175.0 \\
\hline SD & \multicolumn{2}{|c|}{8.4} & \multicolumn{2}{|c|}{10.4} & \multicolumn{2}{|c|}{3.4} & \multicolumn{2}{|c|}{26.4} \\
\hline
\end{tabular}

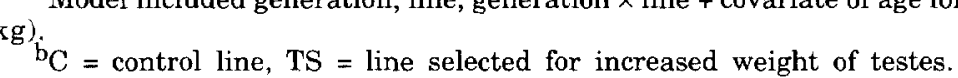

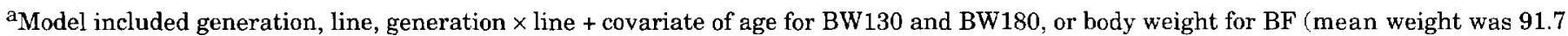

${ }^{c} \mathrm{BW} 130=$ body weight at $130 \mathrm{~d}$ of age, BW180 = body weight at $180 \mathrm{~d}$ of age, BF $=$ average backfat thickness at $91.7 \mathrm{~kg}, \mathrm{AP}=$ age at puberty.
} 
Table 6. Mixed-model estimates of average breeding values by line ${ }^{a}$ and generation (Gen)

\begin{tabular}{|c|c|c|c|c|c|c|c|}
\hline \multirow[b]{2}{*}{ Gen } & \multicolumn{7}{|c|}{ Trait $^{b}$} \\
\hline & $\begin{array}{c}\text { PWT, } \\
\text { g }\end{array}$ & $\begin{array}{c}\text { BW140, } \\
\text { kg }\end{array}$ & $\begin{array}{c}\text { BW160, } \\
\text { kg }\end{array}$ & $\begin{array}{c}\text { BW130, } \\
\text { kg }\end{array}$ & $\begin{array}{c}\text { BW180, } \\
\text { kg }\end{array}$ & $\begin{array}{l}\mathrm{BF}, \\
\mathrm{mm}\end{array}$ & $\begin{array}{c}\mathrm{AP} \\
\mathrm{d}\end{array}$ \\
\hline & & & & Line C & & & \\
\hline 0 & -3.30 & .05 & .06 & .10 & -.15 & -.02 & 2.71 \\
\hline 1 & -5.20 & .06 & .20 & .01 & -.28 & .03 & 4.26 \\
\hline 2 & -4.08 & .28 & .65 & .81 & 1.13 & -.12 & 1.59 \\
\hline 3 & -4.75 & .35 & .64 & 1.05 & 1.38 & -.21 & 1.43 \\
\hline 4 & -8.22 & .38 & .64 & .80 & 1.01 & -.28 & .83 \\
\hline 5 & -10.36 & .61 & .84 & .56 & 1.10 & -.08 & -3.81 \\
\hline 6 & -4.25 & 1.64 & 1.69 & 1.06 & 1.76 & .09 & -6.98 \\
\hline 7 & -4.04 & 2.20 & 2.40 & 1.19 & 2.74 & -.09 & -8.75 \\
\hline 8 & .15 & 2.48 & 2.51 & 1.52 & 3.64 & .14 & -10.47 \\
\hline 9 & -3.06 & 1.88 & 2.02 & 1.52 & 3.91 & .01 & -9.06 \\
\hline 10 & .14 & 2.43 & 2.84 & 1.86 & 3.90 & .19 & -9.00 \\
\hline 0 & 3.30 & -.19 & -.22 & -.14 & .19 & .13 & -2.00 \\
\hline 1 & 33.00 & .21 & .03 & 1.01 & 2.23 & 1.02 & -5.68 \\
\hline 2 & 52.80 & 1.03 & .83 & 1.28 & 2.47 & .98 & -9.25 \\
\hline 3 & 76.03 & 3.10 & 3.01 & 2.93 & 4.96 & 1.45 & -10.46 \\
\hline 4 & $\mathbf{9 7 . 9 0}$ & 4.55 & 5.13 & 3.94 & 6.15 & 1.60 & -11.55 \\
\hline 5 & 120.16 & 5.85 & 6.49 & 4.38 & 6.87 & 1.71 & -9.36 \\
\hline 6 & 135.36 & 6.77 & 7.15 & 5.69 & 8.35 & 1.57 & -10.58 \\
\hline 7 & 155.06 & 8.05 & 8.56 & 7.04 & 9.65 & 1.87 & -12.66 \\
\hline 8 & 174.89 & 9.49 & 10.19 & 7.48 & 10.61 & 1.96 & -14.25 \\
\hline 9 & 191.83 & 10.30 & 11.24 & 7.68 & 11.36 & 2.53 & -15.14 \\
\hline 10 & 204.51 & 10.64 & 11.75 & 7.90 & 12.07 & 2.54 & -14.70 \\
\hline
\end{tabular}

${ }^{\mathrm{a}} \mathrm{C}=$ control line, $\mathrm{TS}=$ line selected for increased predicted weight of testes.

bPWT = predicted weight of testes, BW140= body weight of boars at $140 \mathrm{~d}, \mathrm{BW} 160=$ body weight of boars at $160 \mathrm{~d}, \mathrm{BW} 130$ = body weight of gilts at $130 \mathrm{~d}, \mathrm{BW} 180=$ body weight of gilts at $180 \mathrm{~d}, \mathrm{BF}=$ backfat probe for boars and gilts, AP = age at puberty.

Table 7. The realized heritability of PWT was $.35 \pm$ .05. Similar estimates of change in PWT per generation were obtained by both the regression $(18.5 \pm 2.76$ $\mathrm{g})$ and the mixed-model method $(20.0 \pm .52 \mathrm{~g})$.

All procedures produced significant estimates of increases in body weight of boars at 140 and $160 \mathrm{~d}$ and of gilts at $130 \mathrm{~d}$, and all estimates of response in body weight of gilts at $180 \mathrm{~d}$ were significant except the regression on generation number. Regression estimates of genetic change per generation were $.95 \pm .37$ and $1.13 \pm .42 \mathrm{~kg}$ for boars at 140 and $160 \mathrm{~d}$, respectively, and $.70 \pm .32$ and $.64 \pm .46 \mathrm{~kg}$ for gilts at 130 and $180 \mathrm{~d}$, respectively. Estimates of genetic change in body weight by the mixed-model procedure were significant at each age for both lines for both boars and gilts. The mixed-model estimates of responses in line TS were larger than the regression estimates, but regression estimates were calculated as a deviation from line C. For all body weights, the difference between the genetic trend for the TS and C lines is very similar to the regression estimate of genetic change.

Backfat increased during the experiment in line TS in both boars and gilts. In gilts, the regression on CSD was significant, but regressions of deviations from line
C were not significant in either sex. Significant genetic trend in backfat was found in line TS by the mixed-model procedure, but there was no change in line $\mathrm{C}$.

The response in age at puberty was not consistent over generations. The lines diverged from Generation 0 to 4 , but means for the lines were similar from Generations 5 to 7 . Thereafter, there was again some divergence between the lines (Table 5). Estimates of genetic change by the methods are not consistent (Table 7). The regression on CSD was $-.013 \pm .021$, indicating a small decrease in age at puberty in response to selection for PWT. However, the regression of deviations from line $\mathrm{C}$ on generation was $.80 \pm$ 1.31, indicating that age at puberty increased in line TS relative to line $\mathrm{C}$.

The regression on CSD estimates the response in both lines per unit of selection for PWT while simultaneously adjusting for environmental trend. Therefore, estimates by this method do not have to agree with regressions of deviations of animals in the TS line from the line $\mathrm{C}$ mean, although similar results are expected. The explanation for the discrepancy is that significant genetic decrease in age at puberty was found in line $\mathrm{C}$ by the mixed-model method. Significant genetic decrease also occurred in line TS, but the 
Table 7. Responses to selection estimated by regression on cumulative selection differential (CSD) by

Richardson's method, regressions of deviations of TS line animals from the $\mathrm{C}$ line mean on generation number (Gen), and within-line regressions of average breeding value (BV) obtained with the mixed-model analyses on generation number

\begin{tabular}{|c|c|c|c|c|c|c|c|c|c|}
\hline \multirow[b]{2}{*}{ Trait $^{\mathrm{a}}$} & \multicolumn{4}{|c|}{ Regression on } & \multicolumn{5}{|c|}{ Regression of mean BV on Gen } \\
\hline & $\mathrm{CSD}$ & $\mathrm{SE}$ & Gen & SE & & Line $\mathrm{TS}^{\mathrm{b}}$ & SE & Line $\mathrm{C}^{\mathrm{b}}$ & $\mathrm{SE}$ \\
\hline & & & & & \multirow{5}{*}{ Boars } & & & & \\
\hline PWT, g & $.35^{* *}$ & .045 & $18.5^{* *}$ & 2.76 & & $20.00^{* * *}$ & .52 & .40 & .28 \\
\hline BW140, kg & $.013^{*}$ & .006 & $.95^{*}$ & .37 & & $1.20 * *$ & .05 & $.28^{* * *}$ & .04 \\
\hline BW160, kg & $.015^{*}$ & .007 & $1.128 * *$ & .42 & & $1.32^{* *}$ & .06 & $.28^{* *}$ & .03 \\
\hline $\mathrm{BF}, \mathrm{mm}$ & .003 & .002 & .083 & .14 & & $.20 * *$ & .02 & .02 & .01 \\
\hline BW130, kg & $.010^{*}$ & .005 & $.701^{*}$ & .32 & \multirow{4}{*}{ Gilts } & $.87 * *$ & .05 & $.16^{* * *}$ & .02 \\
\hline BW180, kg & $.014^{*}$ & .007 & .641 & .46 & & $1.20^{* * *}$ & .05 & $.44^{* *}$ & .04 \\
\hline $\mathrm{BF}, \mathrm{mm}$ & $.005^{*}$ & .002 & .158 & .14 & & $.20 * *$ & .02 & .02 & .01 \\
\hline $\mathrm{AP}, \mathrm{d}$ & -.013 & .021 & .804 & 1.31 & & $-1.09 * *$ & .16 & $-1.60 * *$ & .19 \\
\hline
\end{tabular}

${ }^{\text {aPWT }}=$ predicted weight of testes, BW140 = body weight at $140 \mathrm{~d}, \mathrm{BW} 160=$ body weight at $160 \mathrm{~d}, \mathrm{BF}=$ backfat at $85.3 \mathrm{~kg}$, boars, and 91.7 $\mathrm{kg}$, gilts, BW130 = body weight at $130 \mathrm{~d}, \mathrm{BW} 180=$ body weight at $180 \mathrm{~d}$, and AP = age at puberty.

${ }^{{ }} \mathrm{C}=$ control line, $\mathrm{TS}=$ line selected for increased predicted weight of testes.

$* P<.05$.

$* * P<.01$.

change was not as large as in line $\mathrm{C}$. Greater genetic change in line $\mathrm{C}$ than in line TS will cause the regression of deviations from line $\mathrm{C}$ to be positive even though results of both Richardson's method and the mixed-model method were negative estimates of genetic correlation of age at puberty with PWT.

Mean ovulation rate for samples of gilts in Generations 5 and 10 are given in Table 8 . The difference between lines was not significant in Generation 5 . In Generation 10, the difference between lines was nearly twice as large as that in Generation $5(P<$ .10 ).

Estimates of genetic parameters obtained by DFREML in the mixed-model analyses are shown in Table 9. This estimate of heritability of PWT was .39, compared with the realized heritability of .35 . Litter effects accounted for between 13 and $23 \%$ of the phenotypic variance for all traits except body weight of gilts at $180 \mathrm{~d}$ and age at puberty of gilts. Estimates of genetic correlations of body weights with PWT were all between .4 and .5, the genetic correlation of backfat with PWT was .25, and the estimate of the correlation of age at puberty with PWT was -.16.

Estimates of genetic correlations obtained from regressions on CSD also are given in Table 9. For body weight and age at puberty, these estimates are approximately half as large as those obtained from the mixed-model procedure. For backfat, the procedures produced similar estimates. The difference is probably due to the fact that the mixed-model procedure found genetic trend in the control line for body weight and age at puberty, but not for backfat. Because Richardson's method measures response as a deviation of line TS from line $\mathrm{C}$, estimates of genetic trend by this method were smaller. Hence, if genetic trend occurred in line $\mathrm{C}$, estimates of genetic correlations obtained by the regression procedure will be smaller than those obtained by the mixed-model procedure.

\section{Discussion}

The motivation to do this experiment came primarily from two papers. First, Land (1973) found that testis weight (mice) or diameter (sheep) was greater in the mouse lines or sheep breeds with the higher ovulation rate. The physiological pathway underlying this genetic association was not fully understood, but these findings suggested that it might be possible to

Table 8. Number of corpora lutea on both ovaries of gilts sampled from Generations 5 and 10

\begin{tabular}{lcccccc}
\hline & \multicolumn{2}{c}{ Line TS $^{\mathrm{a}}$} & & \multicolumn{2}{c}{ Line $\mathrm{C}^{\mathrm{a}}$} & \\
\cline { 2 - 3 } Generation & $\mathrm{n}$ & $\overline{\mathrm{x}}$ & & $\mathrm{n}$ & $\overline{\mathrm{x}}$ & Difference \\
\hline 5 & 32 & 13.20 & & 31 & 12.80 & $.40 \pm .62$ \\
10 & 42 & 12.81 & & 40 & 12.05 & $.76 \pm .43$ \\
\hline
\end{tabular}

${ }^{\mathrm{a}} \mathrm{TS}=$ line selected for increased predicted weight of testes, $\mathrm{C}=$ control line. 
Table 9. Estimates of genetic parameters obtained by DFREML and of genetic correlations with predicted weight of testes obtained from regressions on cumulative selection differentials $\{\mathrm{CSD}\}$

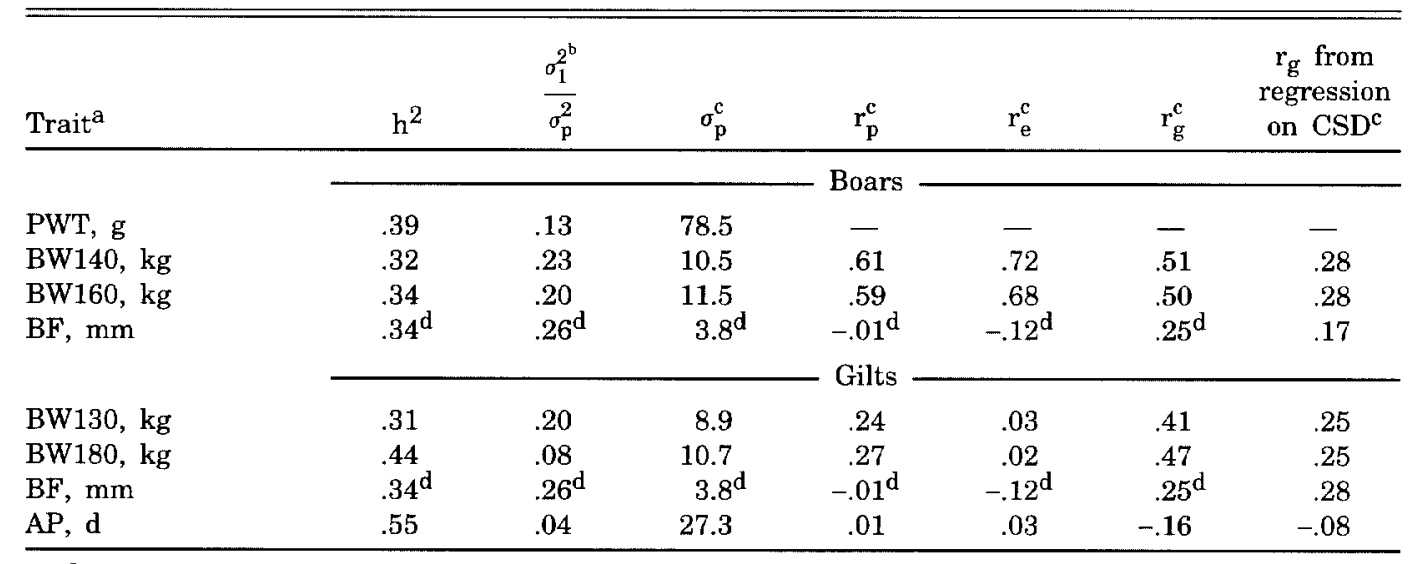

${ }^{\text {aPWT }}=$ predicted weight of testes, BW140 = body weight at $140 \mathrm{~d}, \mathrm{BW} 160=$ body weight at $160 \mathrm{~d}, \mathrm{BF}=$ backfat, BW130 = body weight at $130 \mathrm{~d}, \mathrm{BW} 180$ = body weight at $180 \mathrm{~d}$, and AP = age at puberty. ${ }^{b}$ Ratio of litter variance to phenotypic variance.

${ }_{r_{p}}, r_{e}$, and $r_{g}$ are phenotypic, environmental, and genetic correlations, respectively, with PWT.

dPooled estimates for boars and gilts from mixed-model analysis that included sex in the model.

base genetic selection for increased fertility in the female on reproductive characteristics of males. If the male trait is moderately to highly heritable and has a high genetic correlation with the female traits, more rapid response to selection might be possible because higher selection differentials can be achieved in males (Falconer, 1989, p 318).

The second important background paper is that by Islam et al. (1976). They selected for both increased and decreased testis weight in the mouse for five generations. The mean divergence between lines was approximately $60 \%$ of the base population mean. The line selected for increased testis weight had higher ovulation rate ( 2 eggs in Generation 4 and 1.6 eggs in Generation 5). The realized heritability of testis weight was .52 and line differences in ovulation rate of nulliparous and primiparous females corresponded to genetic correlations with testis weight of .25 and .50 , respectively. Based on these two papers, we hypothesized that selection for increased size of testes in boars would increase ovulation rate in females.

The anterior pituitary secretes $\mathrm{LH}$ and FSH, hormones with gonadotrophic activity (Hadley, 1984). In females, LH stimulates ovulation and corpora lutea formation. Recruitment and development of ovarian follicles is stimulated by FSH. Both LH and FSH have a role in the onset of puberty. In males, LH stimulates synthesis and secretion of testosterone by the interstitial cells of Leydig and is therefore indirectly responsible for the development of sex characteristics. The action of $\mathrm{LH}$ is dependent on the FSH induction of $\mathrm{LH}$ receptors on Leydig cells. The FSH is responsible for the initial steps of germ cell maturation, and testosterone is required for complete maturation. Spermatogenesis is stimulated directly by FSH and indirectly by the effect of LH on testosterone synthesis by Leydig cells. An increase in the size of the testes is due to an increase in the diameter and length of the seminiferous tubules and an increase in the number of Leydig cells (van Straaten and Wensing, 1977, 1978; Allrich et al., 1983).

These underlying physiological mechanisms suggest that selection for larger testes at a constant age should decrease age at puberty in both males and females. Schinckel et al. (1984) did find higher concentrations of LH and the presence of spermatogenesis at earlier ages in boars with heavier testes than in boars with lighter testes. Further, Schinckel et al. (1983) reported negative correlations between testis size and age at puberty of full-sibs and dams.

In our experiment, the realized heritability of PWT was .35 and the difference in ovulation rate of .76 eggs between the TS and $\mathrm{C}$ lines in Generation 10 corresponds to a genetic correlation of approximately .10 ; both values are lower than those reported by Islam et al. (1976). Further, Eisen and Johnson (1981), after 22 generations of selection for large litter size in mice, found a realized genetic correlation of . $60 \pm .04$, before adjustment for body weight, and .42 after adjustment, between testis weight and litter size. Hill et al. (1990b) also reported a correlated increase in litter size after 11 generations of selection for testis weight. In mice, the association between ovulation rate and litter size is high (Gion et al., 1990); therefore, our results indicate a lower genetic association between ovulation rate and testis weight in swine than in mice.

Although negative, the realized genetic correlation between age at puberty in gilts and PWT was very low. Thus, indirect selection for PWT to decrease age at puberty was not effective. These results are similar to those reported for sheep. The realized heritability of 
testis diameter was $.40 \pm .08$ (Land et al., 1980), but after $9 \mathrm{yr}$ of selection, age at puberty of ewe lambs was not affected (Lee and Land, 1984).

The response per generation in PWT was $5.5 \%$ of the base generation mean. Correlated responses in body weight of boars and gilts between 130 and $180 \mathrm{~d}$ ranged from .7 to $1.6 \%$ per generation and backfat increased at a rate of $.4 \%$ per generation in gilts and $.8 \%$ in boars. Testis weight and body weight were correlated $\left(r_{g}=.50, r_{p}=.60\right.$; Table 9); however, approximately $64 \%$ of the phenotypic variation in testis weight was independent of body weight. Similarly, Schinckel et al. (1984) found that the majority of the difference between boars with heavy and light testis weights was independent of body weight, and Allrich et al. (1981) found that adjustment for body weight did not remove differences in testis weight between lines of rats selected for rate of lean growth.

The correlated increase in backfat that occurred when selection was for PWT suggests that the TS line may mature earlier than the $\mathrm{C}$ line. Boars with heavier testis weight also had more backfat (Schinckel et al., 1984). These results are consistent with the hypothesis proposed by Land et al. (1980) that selection for testis weight in sheep gradually changes the relative maturity of animals. Although differences in fat were not reported for the lines selected for increased and decreased testis diameter, they suggested that selection for large testes may favor earlymaturing animals. Hill et al. (1990a) tested this hypothesis by jointly selecting for all combinations of increased and decreased body weight and testis size. Minor changes in the shape of the growth curve occurred; lines selected for increased testis weight had earlier maturity. However, they could not establish whether size of testes is an indicator of sexual maturity.

Results of two analyses are presented, and although estimates of responses by the methods are similar, they can have somewhat different interpretations. Regression analyses estimate responses to selection applied for increased PWT. Comparisons of the select and control line measure the effect of artificial selection and random genetic drift in the select line to the natural or unintended selection and genetic drift in the control line. The estimates of realized heritability and genetic correlations pertain to a population undergoing selection in one direction. No assumption is made about symmetrical correlations and the estimates do not indicate what response might be expected from several generations of selection for decreased PWT.

Both the regressions of mixed-model EBV on generation number and regressions of line differences on generation number in the regression analyses estimate genetic trend. Regressions from the two analyses should not always be expected to agree. Regressions are similar for PWT in this experiment because estimates of heritability by the two methods are similar. The regression estimate of realized heritability is from response and cumulative selection differential, whereas the mixed-model estimate is from similarities between relatives. The former estimate is from a population undergoing selection, whereas variance and covariance components from mixedmodel analyses are estimated relative to the base population, and are thus approximately equivalent to those estimated in a large, random mating, unselected population. Therefore, estimates from mixed-model analyses are for what might be expected from selection in the base population. Correlations are assumed to be symmetrical. Regression estimates show what happened when selection was applied. Comparisons of the estimates by the two methods are useful to determine how well estimates from base populations predict response to several generations of directional selection. In this experiment, results from the two analyses were reasonably similar.

\section{Implications}

Testis weight is a heritable, highly variable trait that can be increased by selection in swine. Correlated increases in body weight and backfat can be expected. Estimates in the literature suggest that testis size may also be a useful indicator trait to indirectly select for female reproductive traits. However, in this experiment, correlated responses in ovulation rate and age at puberty were small and not significant. Therefore, it is not recommended that testis weight be used as an indicator trait to select for female reproductive traits in swine. Work has been done with boars from these lines and will soon be reported to determine whether selection for testis weight has changed male fertility traits.

\section{Literature Cited}

Allrich, R. D., R. K. Christenson, J. J. Ford, and D. R. Zimmerman. 1983. Pubertal development of the boar: Age-related changes in testicular morphology and in vitro production of testosterone and estradiol-173. Biol. Reprod. 28:902.

Allrich, R. D., C. T. Wang, G. E. Dickerson, and D. R. Zimmerman. 1981. Selection for increased rate or efficiency of lean growth in rats: Correlated responses in reproductive performance. J. Anim. Sci. 53:1458.

Boldman, K. G., L. A. Kriese, L. D. Van Vleck, and S. D. Katchman. 1993. A manual for the use of MTDFREML: A set of programs to estimate variances and covariances. Agric. Handbook, ARS, USDA, Washington, DC (In press).

Boldman, K. G., and L. D. Van Vleck. 1991. Derivative-free restricted maximum likelihood estimation in animal models with a sparse matrix solver. J. Dairy Sci. 74:4337.

Eisen, E. J., and B. H. Johnson. 1981. Correlated responses in male reproductive traits in mice selected for litter size and body weight. Genetics 99:513.

Falconer, D. S. 1989. Introduction to Quantitative Genetics (3rd Ed.). John Wiley \& Sons, New York. 
George, A., J. Liu, and E. Ng. 1980. User Guide for Sparspak: Waterloo Sparse Matrix Linear Equations Package. Univ. of Waterloo, ON, Canada.

Gion, J. M., A. C. Clutter, and M. K. Nielsen. 1990. Alternative methods of selection for litter size in mice: II. Response to 13 generations of selection. J. Anim. Sci. 68:3543.

Graser, H.-U., S. P. Smith, and B. Tier, 1987. A derivative-free approach for estimating variance components in animal models by restricted maximum likelihood. J. Anim. Sci. 64:1362.

Hadley, M. C. 1984. Endocrinology. Prentice-Hall, Englewood Cliffs, NJ.

Hanrahan, J. P., and J. F. Quirke. 1977. Testis size and plasma luteinizing hormone as aids to selection for fecundity in sheep. Anim. Prod. 24:148 (Abstr.).

Hill, W. G. 1972. Estimation of realized heritabilities from selection experiments. II. Selection in one direction. Biometrics 28:767.

Hill, W. G., P. J. Marks, J. C. Jenkins, and R. B. Land. 1990a. Selection on testis size as an indicator of maturity in growing animals. I. Direct and correlated responses in growth. Genet. Sel. Evol. 22:231.

Hill, W. G., P. J. Marks, J. C. Jenkins, and R. B. Land. 1990 b. Selection on testis size as an indicator of maturity in growing animals. II. Correlated responses in reproductive rate. Genet. Sel. Evol. 22:247.

Islam, A.B.M., W. G. Hill, and R. B. Land. 1976, Ovulation rate of lines of mice selected for testis weight. Genet. Res. 27:23.

Land, R. B. 1973. The expression of female sex-limited characters in the male. Nature (Lond.) 241:208.

Land, R. B., and W. R. Carr. 1975. Testis growth and plasma LH concentration following hemicastration and its relation with female prolificacy in sheep. J. Reprod. Fertil. 45:495.

Land, R. B., W. R. Carr, and G. J. Lee. 1980. A consideration of physiological criteria of reproductive merit in sheep. In: A. Robertson (Ed.) Proc. Symp. Selection Experiments in Laboratory and Domestic Animals, July 21-22, 1979, Commonwealth Agric. Bureaux, Harrogate, U.K.

Lee, G. J., and R. B. Land. 1984. Testis size and LH response to LH$\mathrm{RH}$ as male criteria of female reproductive performance. In: $\mathrm{R}$.
B. Land and D. W. Robinson (Ed.) Genetics of Reproduction in Sheep. pp 333-341. Butterworths, London.

Meyer, K. 1988. Programs to estimate variance components for individual animal models by restricted maximum likelihood. User notes. Univ. of Edinburgh, U.K.

Notter, D. R., G. E. Dickerson, and J. A. DeShazer. 1976. Selection for rate and efficiency of lean gain in the rat. Genetics 84:125.

NRC. 1988. Nutrient Requirements of Swine (9th Ed.). National Academy Press, Washington, DC.

Proud, C., D. Donovan, R. Kinsey, P. J. Cunningham, and D. R. Zimmerman. 1976. Testicular growth in boars as influenced by selection for ovulation rate. J. Anim. Sci. 42:1361 (Abstr.).

Richardson, R. H., K. Kojima, and H. L. Lucas. 1968. An analysis of short-term selection experiments. Heredity 23:493.

Rutledge, J. J., E. J. Eisen, and J. E. Legates. 1973. An experimental evaluation of genetic correlation. Genetics. 75:709.

SAS. 1988. SAS/STAT ${ }^{\circledR}$ User's Guide (Release 6.03). SAS Inst. Inc., Cary, NC.

Schinckel, A. P., R. K. Johnson, and R. J. Kittok. 1984. Testicular development and endocrine characteristics of boars selected for either high or low testis size. J. Anim. Sci. 58:675.

Schinckel, A., R. K. Johnson, R. A. Pumfrey, and D. R. Zimmerman. 1983. Testicular growth in boars of different genetic lines and its relationship to reproductive performance. J. Anim. Sci. 56: 1065.

Smith, S. P., and H.-U. Graser. 1986. Estimating variance components in a class of mixed models by restricted maximum likelihood. J. Dairy Sci. 69:1156.

Sorensen, D. A., and K. Johansson. 1992. Estimation of direct and correlated responses to selection using univariate animal models. J. Anim. Sci. 70:2038.

Steel, R.G.D., and J. H. Torrie. 1960. Principles and Procedures of Statistics. McGraw-Hill Publishing Co., New York.

van Straaten, H.W.M., and C.J.G. Wensing. 1977. Histomorphometric aspects of testicular morphogenesis in the pig. Biol. Reprod. $17: 467$.

van Straaten, H.W.M., and C.J.G. Wensing. 1978. Leydig cell development in the testis of the pig. Biol. Reprod. 18:86. 